\title{
Quality of Service in Motor Insurance on the Example of Polish: The Author's Own Research*
}

\author{
Jarosław Wenancjusz Przybytniowski \\ Jan Kochanowski University, Kielce, Poland
}

\begin{abstract}
Dynamic development of companies providing services for potential clients, together with the growing competition, indicates the need for increased actions and practices aimed at the improvement of the quality of their offered services. An example of that is the Toyota Company which, thanks to its approach, has totally changed our line of thinking about methods of quality improvement. The recognition of specific customer needs and their domination over the competitors in every area of company operations, assessed in terms of quality, makes the quality perceived not only as an aim, but also as a whole organization functions. The aim of this work is to identify and analyse the factors (areas) determining the level of service provision in the business insurance market in the opinions of customers using the AUTOCASCO (comprehensive car insurance) insurance, by means of the Servqual method. The research tool used by the authors is a questionnaire. Based on the above aim, the thesis is formed that the insurance service quality is determined by certain factors, connected with the promptness of response to customer needs.
\end{abstract}

Keywords: service quality, insurance service, quality management

The problem of quality has become one of the most important issues in the modern world. Entrepreneurs, in order to strengthen their market position (Wasiewicz, 1994), improve technologies, develop the quality of goods and services they offered, and first and the foremost, adapt to the more and more stringent standards. Quality is a significant element of the mission of Toyota, a car producer (Liker \& Hoseus, 2009). The driving force of Toyota success is skillful balancing the role of people in the organizational culture which expects constant improvement and rewarding, together with the technical system oriented at the flow creating a high added value of the company (Liker \& Ogden, 2011). Here, the author refers to the definition of toyotarity. Toyotarity is a legally protected concept. It is a scientific discipline examining the relationship between man and machine, and man and man, bearing in mind the process-based approach, Japanese culture, especially the Toyota culture, oriented at the continuous improvement and the use of knowledge (Borkowski, 2012). Simultaneously, the author emphasizes that Toyota is building its market position mainly on the basis of quality arguments such as durability and reliability. The Toyota Company is an example of an intelligent organization whose main aim is product quality and customer loyalty.

Efficiency and professional customer service are one of the most important factors, determining the

\footnotetext{
* This paper is the effect of research conducted by the author for the research project No. 614538 .

Corresponding author: Jarosław Wenancjusz Przybytniowski, Ph.D., Institute of Management, Jan Kochanowski University; research fields: ecology and changes in the environment, evaluation of changes in an ecosystem and the influence on catastrophic risks and costs that arise in this respect, the financial market, including insurance, knowledge management in the financial market (banks and insurance), as an alternative financing of damage to the environment. E-mail: j.w.przybytniowski@wp.pl.
} 
quality of the perceived company. These factors are the key source of company competitiveness in the market. Customer service quality is created by people who, by their appropriate or inappropriate service, may influence the company image, its development and its financial result (Chłodnicki, 2005). Numerous surveys and experience show that one of the crucial factors, determining the effectiveness and efficiency of employees in the area of customer service are the so-called soft skills ${ }^{1}$. A peculiar example of such skills is empathy, i.e., understanding customer needs and situation, which helps the employee not only to correctly define customer needs, but also to respond to them in a proper way (Siemieniako, 2010). Proper combination of specific competences, together with the set of appropriate soft skills, makes a customer service employee more efficient and effective in performing his/her tasks.

The aim of this work is to identify and analyse factors (areas) determining the level of service provision in the business insurance market in the opinions of customers using the AUTOCASCO (comprehensive car insurance) insurance, by means of the Servqual method. The research tool used by the author is a questionnaire. Based on the above aim, the thesis was formed that the insurance service quality is determined by certain factors, connected with the promptness of response to customer needs.

\section{Defining Service Quality in the Company Environment}

"Quality is not all but all is becoming nothing without quality"- this statement formed by T. J. Peters and R. H. Waterman (2011), is becoming particularly important today in relation to the service sector in Poland. In the area of services, quality is beginning to be the subject of increased interest in theoretical deliberations, as well as in practice.

Service quality is becoming an unusually important concept, particularly for people creating and managing the company strategy as the quality is the main determinant of customer satisfaction and loyalty to service companies, which is closely connected with the profitability of the company providing services (Payne, 1996). In the subject literature, the concept of service is understood as any human business activity of intangible nature which is an interaction between the customer and the service provider ${ }^{2}$. Thus, in the current, ever changing environment, the service cannot function independently but should integrate in itself such elements as customer service, the quality and marketing of such a service, at each step of its realization. To conclude these short deliberations, we may quote the view held by J. Welch (2005), the chairman and CEO (chief executive officer) in General Electric. He says that "Quality is our best assurance of customer allegiance. It is our strongest defense against foreign competition and the only path to sustained growth and earnings". It is generally thought that quality assessment leads to various types of positive economic effects, and, what is more, to the improvement of the whole community welfare. Therefore, quality assessment and improvement in every sphere of economy is for the benefit of the society. However, it plays a particular role in the service sector (see Figure 1).

The most characteristic in the service sector is the increasing, tough competition (Leśniewski, 2013), both home and abroad. The supply offer of service providers is adjusted to market needs thanks to the possibilities created by the use of modern technologies. It is becoming essential to seek other instruments of competitive battle for the customer. Service companies should make deliberate efforts, in accordance to their marketing orientation, taking into account the needs of the current and the potential customer (Garczarczyk, 2004). A customer is the best investment which can bring a number of benefits, most of all, financial ones (Rudawska, 2000).

\footnotetext{
${ }^{1} \mathrm{http} / / /$ www.bankier.pl/wiadomosc/Umiejetnosci-miekkie-kluczem-do-sukcesu2703632.html.

${ }^{2} \mathrm{http} / / /$ www.mfiles.pl/pl/index.php/Usługa.
} 


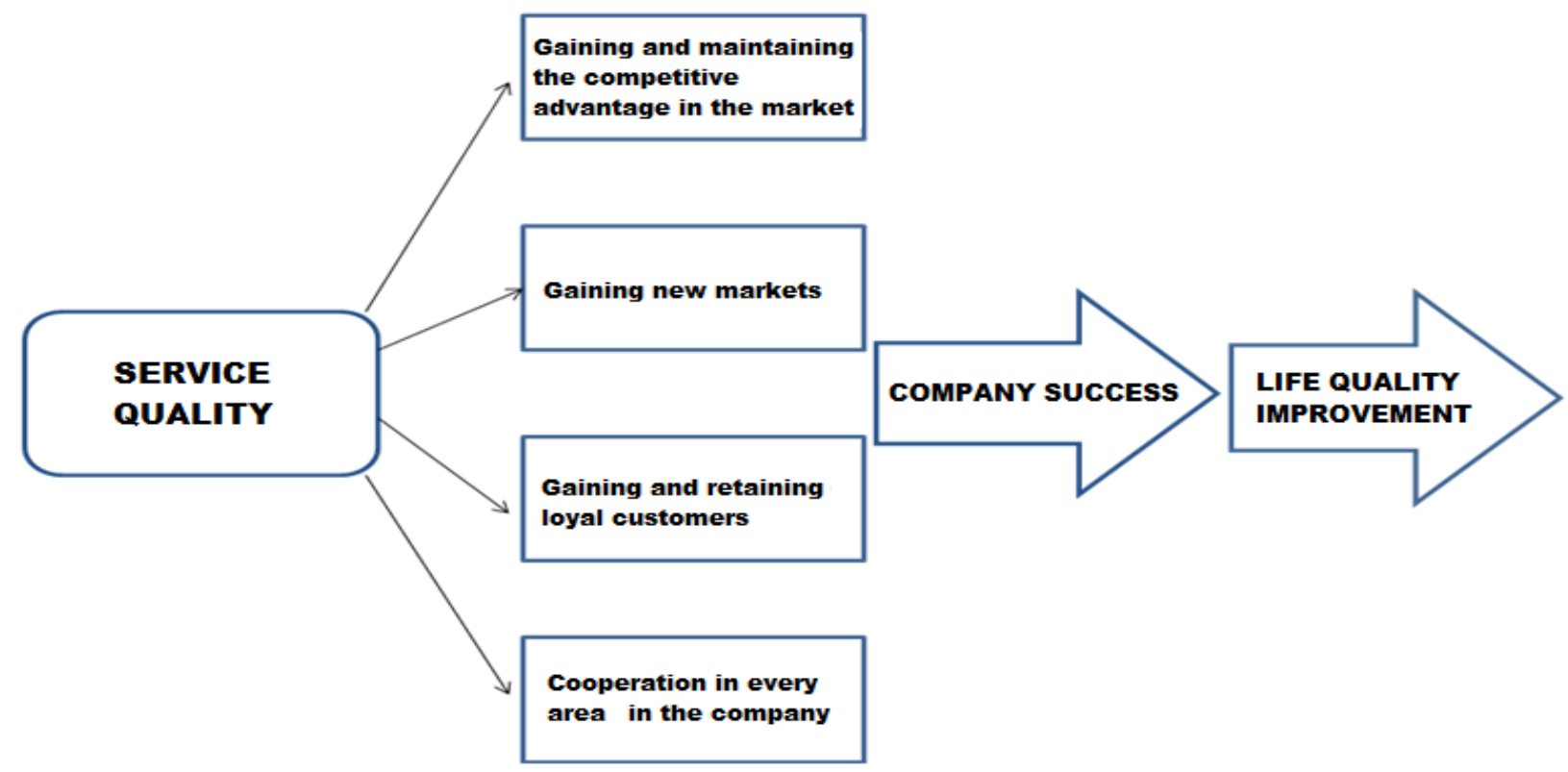

Figure 1. Importance of service quality in company success. Source: Stoma (2012).

In the contemporary market, the quality of services provided is becoming the solid foundation for building firm relations with customers. Whereas, K. Rogoziński (2005) claimed that service quality is the ability to meet customer needs that is the realization which meets or exceeds the buyer's expectations (...). Moreover, the author points to the time aspect of service quality. Service quality assumes that the opinion on quality is extended in time and lasts longer. Furthermore, the quality assessment formed by the service buyer results from two time dimensions overlapping each other - the expectations formed in the past are updated and verified the moment, the assessment (of quality) is formed by the experienced (perceived) quality. It may be concluded that this definition is an attempt to integrate all the approaches to this issue.

Traditionally understood marketing causes that the marketing activities (Przybytniowski \& Lubas, 2009; Przybytniowski, 2011), customer service, and quality are treated as separate, independent issues not integrated in the company management (see Figure 2). Proper quality policy needs active commitment of the company management whose task is to consistently initiate and monitor pro-quality activities (Przybytniowski, 2003).

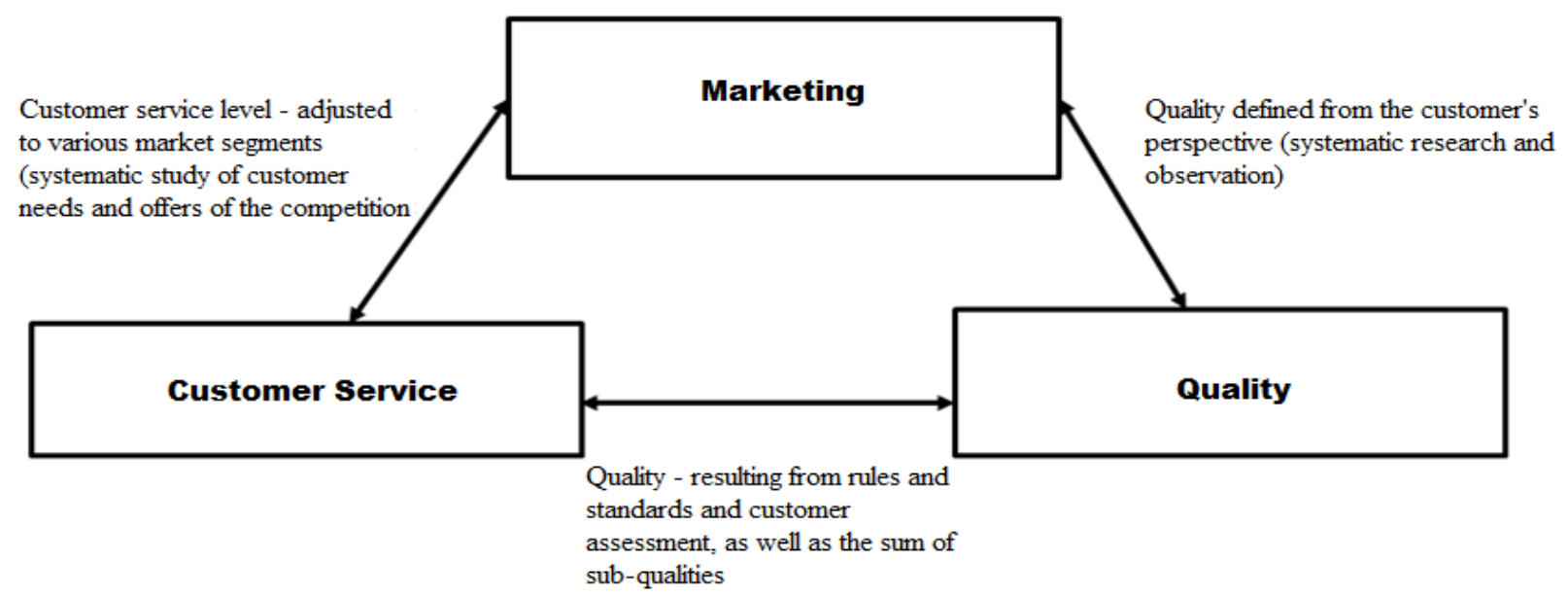

Figure 2. Customer service quality and marketing activities in the process of service provision. Sources: Payne (1996); Przybytniowski (2013). 


\section{Insurance Service Quality}

Insurance activity is very specific. Knowing and meeting customer needs is closely connected with the improvement of the quality of services provided not only by the insurers themselves but also by insurance intermediaries (Kowalewski, 2006; Przybytniowski, 2013; Przybytniowski, 2010; Przybytniowski, 2002).

According to M. Romanowska and M. Trocki (2004), insurance service can be defined as "Meeting the expectations and requirements of the insured by performing actions that make up this service. Insurance service quality results from the use of some basic principles in insurance cover: feasibility, completeness, universality and speed of compensation payment". Bearing in mind the service quality in the insurance sector, it must be remembered that the character of this service results from its intangible, inseparable, and perishable nature. This service is complex and non-homogeneous, which makes insurance service quality difficult to clearly define and measure (Przybytniowski, 2013).

The quality assessment of services offered by insurance institutions includes customer expectations as to the quality of the service and the perception of this service (Szromnik, 1998; Szromnik, 2001; Sułkowska, 2000; Rogoziński, 2000; Storbacka \& Lehtinen, 2001; Grönroos, 1984). Service perception is a subjective feeling experienced by a customer during its acquisition and realization. The customer, as well as the service provider, creates the indicators (attributes) of insurance service quality.

We can distinguish three levels of customer expectations to services (Zeithaml \& Bitner, 1996):

(1) Desired service which reflects customer's desires;

(2) Appropriate service, i.e., what the customer is able to accept;

(3) Expected service, i.e., what the customer thinks that he/she should receive.

Each of the above levels plays a different part when the customer forms his requirements toward service quality (Chłodnicki, 2005). One of the tasks of an insurance institution is to create the belief in professionalism and competence in relations with a customer. The role of the employees of an insurance institution is to show the customer new conditions and make the customer aware of their existence, particularly because the damage liquidation process is one of the basic measurements, determining the assessment of service provision quality (Niestrój, 2004). Here, it should be remembered that the quality of service provision is expressed by the increase in customer satisfaction, the improvement of productivity and performance (efficiency), as well as the noticeable increase in a given service in the market (Garczarczyk, 2004).

In insurance, there are three elements contributing to the above (Gierszewska \& Romanowska, 2009; Zeithaml \& Bitner, 1996):

(1) Internal perfection, effectiveness, and efficiency;

(2) The highest level of customer service;

(3) The organizational structure the shape of which is aimed at supporting a quality organization.

To sum up the above deliberations, first of all, it is necessary to identify and define the determinants of insurance service and, then, to determine their importance in relation to the supply side and the demand side that expects the service appropriate to their needs and expectations.

\section{Methods of Quality Assessment in the Insurance Market Sector}

Reliable data collection and their skillful interpretation are a starting phase in creating quality systems (Haffer \& Karaszewski, 2009). The classics of quality management usually never try to form a final definition 
of this concept but tend to form quality determinants or dimensions, creating various models called service quality models (Johnston, 1995).

One of the theoretical models which is used to study service quality assessment is the gap model (see Figure 3) (Parasuraman, Zeithmal, \& Berry, 1985). This concept assumes that the intentional distinction between individual gaps results from the defects which appear in the course of preparing and providing a service. This model distinguishes five gaps in quality assessment. Gaps 1-4 refer to the fall in quality inside the company, while Gap 5 refers to the service quality assessed by a customer. The reasons for that are certain discrepancies between the service provider and the service receiver during the process of service provision (Zeithaml \& Bitner, 1996).

On the basis of the model below, we may conclude that by appropriate quality management, influencing the company organizational structure and internal communication, we can avoid new gaps to appear (F. Ferrell \& W. Ferrell, 1994), or eliminate the already existing sources of discrepancy which may arise in the entire course of the process of service provision. Nevertheless, it is important to undertake control actions during the whole process.

A different view on service quality (Rogoziński, 2000) is presented by the model prepared by Grönroos (1978; 1984). The concept of this model distinguishes two categories of service quality - technical quality and functional quality. The result of operational processes, i.e., benefits for the customer, resulting from this service provision, constitutes the technical dimension; whereas, the functional dimension describes the process of service provision as perceived by the customer.

The perception of quality by customers includes both the final result as well as the whole process of providing the service (Hemmasi, Strong, \& Taylor, 1994).

The dimensions presented above give the answers to the following questions:

(1) What a service provider offers to the customer?

(2) How a customer/buyer is served by a service provider?

Moreover, we should pay attention to the links and correlations existing between these two quality types. Firstly, the improvement of technical quality has a significant impact on functional quality. Secondly, the interrelations between these areas not only raise the value of the service in the eyes of the customer, but also become an important factor of competitive advantage in the market. In order to fully assess the quality of a given service process, one should consider the so-called expected quality, which is a measure of the confrontation of expectations and demands in the mind of a potential buyer (Garczarczyk, 2002). The above described categories of service quality are presented in Figure 4.

The concept proposed by Grönross, is the key category of every marketing strategy formed by companies dealing in the service sector. It can be concluded that the total service quality assessment includes itself both objective and subjective aspects (Grönross, 2000). Contrary to the assumptions of Grönroos's model, a Swedish researcher E. Gummesson proposed an extended quality model by introducing the sub-qualities (4Q), i.e., design quality, production quality, delivery quality, and relationship quality (Gummesson, 1987; Gummesson, 1996). The author saw the need for the hierarchy in the quality process according to how time-consuming and difficult to realize the service is for the customer (Rogoziński, 2000). Moreover, these elements are a prerequisite of perceived quality and buyer's satisfaction. However, both of the models assume that the buyer's assessment has the greatest impact on service quality. 
Models prepared by Parasuraman, Grönroos, and Gummesson are a significant contribution to the theory of management and their authors became pioneers in creating the concept of customer importance in service quality assessment.

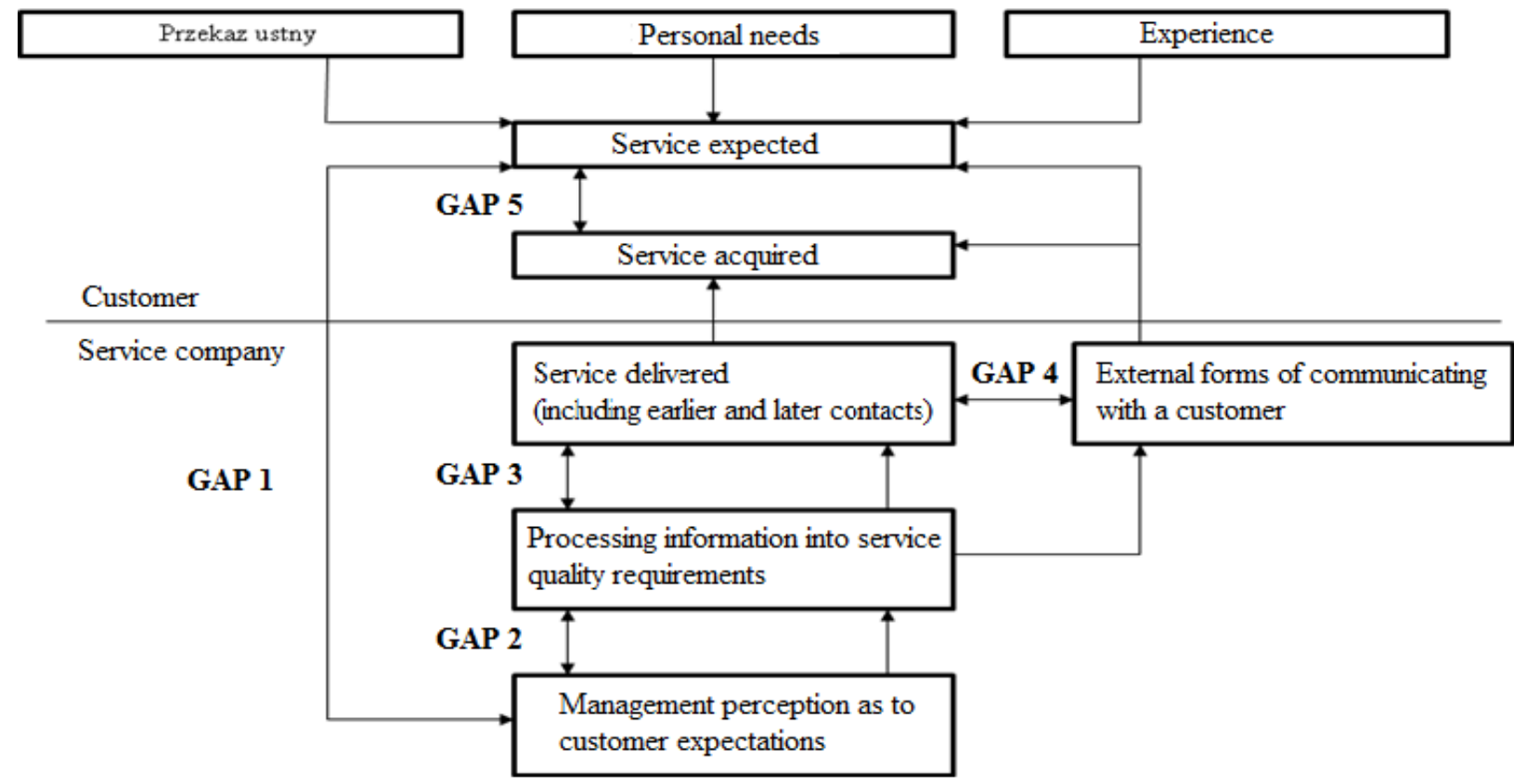

Figure 3. Service quality model based on the Gap Model. Source: Parasuraman et al. (1985).

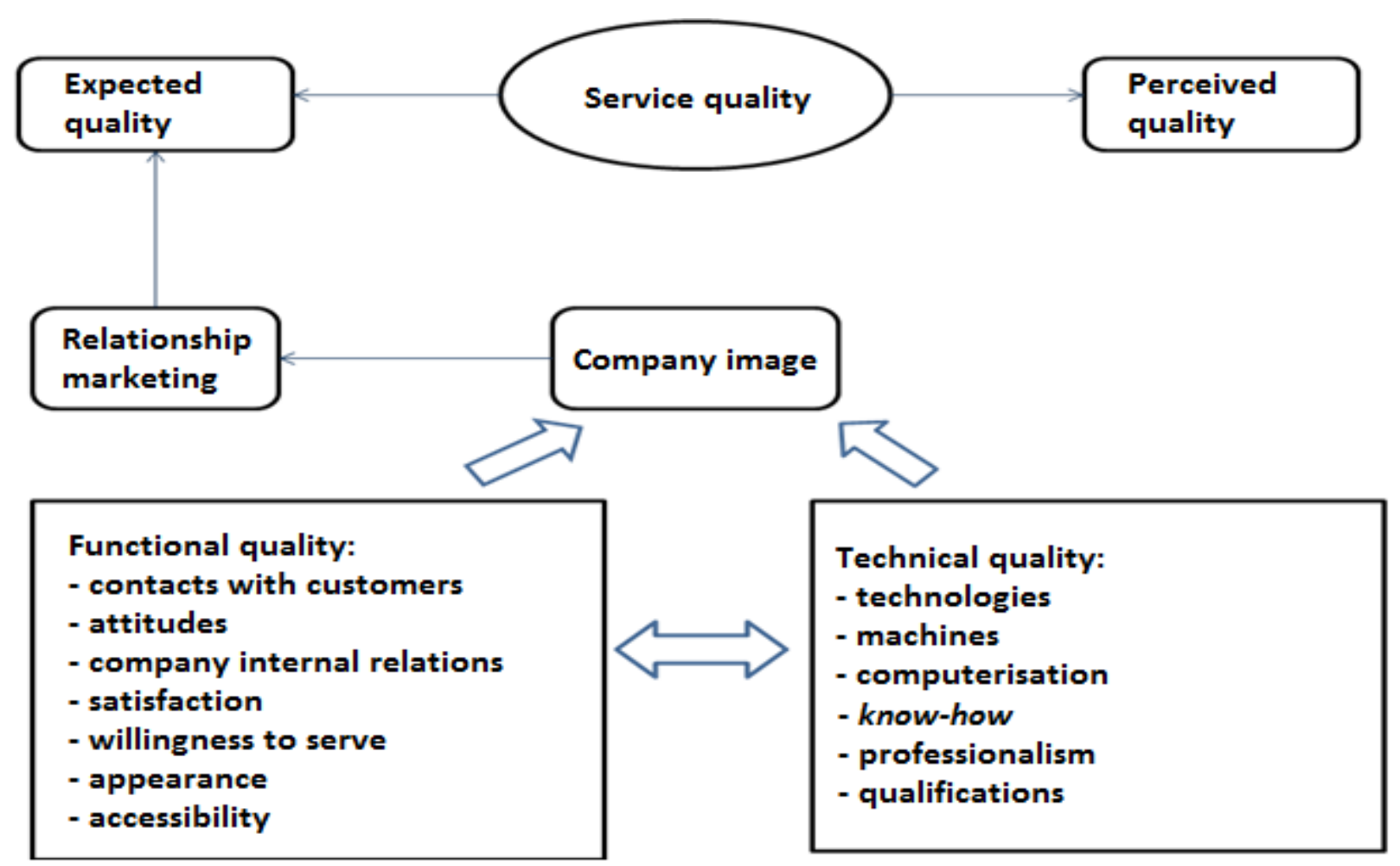

Figure 4. Technical and functional model of service quality, according to Ch. Grönross. Source: Grönross (1984). 


\section{The Analysis of Insurance Service Quality in the Opinion of Customers: The Author's Own Research}

Insurance service quality assessment was presented using the Servqual method. The application of the Servqual method (Johnston, 1995) enables us to define customer expectations and the gap between what the customer expects and what the service provider delivers. The aim of the research is to identify and analyze factors (areas), influencing the level of quality of service provision in the business insurance market, in the opinion of customers using the AUTOCASCO insurance. The study was conducted by means of a questionnaire among individual customers residing in the territory of Świętokrzyskie Voivodship in the years 2012-2013, with insurance agents participating in direct contact with the customers. The questionnaire consisted of 12 questions, four of which referred to general issues and sociodemographic data. The respondents were chosen according to the following criteria:

(1) They had direct contact with the insurance agent;

(2) They held the AUTOCASCO insurance contract;

(3) They went through the damage liquidation procedure;

(4) They reached the age of 18.

There were 150 questionnaires handed out. After verification, in 2012, there were 124 questionnaires analyzed $(82.7 \%)^{3}$, while in 2013,119 questionnaires were verified $(79.4 \%)$. The details are presented in Table 1.

The customer survey on AUTOCASCO insurance service used the scale from 1 to 7 (" 1 "- -very poor, and "7"- excellent). Insurance service quality assessment was calculated on the basis of the difference between customer expectation and customer perception of the service provided. It enabled to find the gap between those two values, as well as to indicate the place in which it is necessary to make changes. The survey analysis was divided into three stages:

(1) To establish the differences between subsequent expectations and perceptions expressed in points;

(2) To calculate the average point difference in each of the studied areas;

(3) To use the Semiquaver method to calculate the total arithmetic measurement of the studied service quality.

Table 1

The Structure of Respondents According to the Criteria in the Territory of the Świętokrzyskie Voivodship in the Years 2012-2013 (in \%)

\begin{tabular}{|c|c|c|c|c|c|c|c|}
\hline \multirow[t]{2}{*}{ Criterion } & \multicolumn{4}{|c|}{$\begin{array}{l}\text { Number of respondents according to the selected } \\
\text { answer }\end{array}$} & \multicolumn{3}{|c|}{$\begin{array}{l}\text { Number of respondents according to the selected } \\
\text { answer }\end{array}$} \\
\hline & \multicolumn{4}{|l|}{2012} & \multicolumn{3}{|l|}{2013} \\
\hline Number of respondents & \multicolumn{4}{|l|}{124} & \multicolumn{3}{|l|}{119} \\
\hline \multirow{2}{*}{ Place of residence } & \multirow{2}{*}{\multicolumn{2}{|c|}{$\begin{array}{l}\text { Town } \\
67(54 \%)\end{array}$}} & \multirow{2}{*}{\multicolumn{2}{|c|}{$\begin{array}{l}\text { Village } \\
57(46 \%)\end{array}$}} & \multirow{2}{*}{\multicolumn{2}{|c|}{$\begin{array}{l}\text { Town } \\
71(59.7 \%)\end{array}$}} & \multirow{2}{*}{$\begin{array}{l}\text { Village } \\
48(40.3 \%)\end{array}$} \\
\hline & & & & & & & \\
\hline \multirow[b]{2}{*}{ Age } & To 65 & $36-45$ & & 45 or more & To 35 & $36-45$ & 45 or more \\
\hline & $27(21.8 \%)$ & $\begin{array}{l}59 \\
(47.6 \%)\end{array}$ & & $38(30.6 \%)$ & $\begin{array}{l}25 \\
(21 \%)\end{array}$ & $\begin{array}{l}54 \\
(45.4 \%)\end{array}$ & $\begin{array}{l}40 \\
(33.6 \%)\end{array}$ \\
\hline
\end{tabular}

Note. Source: based on the author's own research.

${ }^{3}$ The figures of 2012 are a result of the previously conducted survey and analyses, see: Przybytniowski, J. W. (2013), Kształtowanie konkurencyjności rynku ubezpieczeń gospodarczych (Competitiveness in the business insurance market). In R. Borowiecki and A. Jaki, Restructuring of firms and economies in terms of development of global markets (pp. 390-394). Foundation of the University of Economics in Krakow, Krakow, Krakow. 
Figure 5 presents five areas of insurance service quality as assessed by customers using AUTOCASCO in 2013. The average result for all the areas was at the level of -2.13 , which means that in comparison with the previous year $(-1.94)$, the value rose slightly by -0.19 . This upward trend shows the existence of a clear discrepancy between the expectations of customers of insurance institutions and the quality of services provided in individual areas. It may be stated that the way the service is provided is not consistent with customer expectations and, consequently, the quality of the service is unsatisfactory.

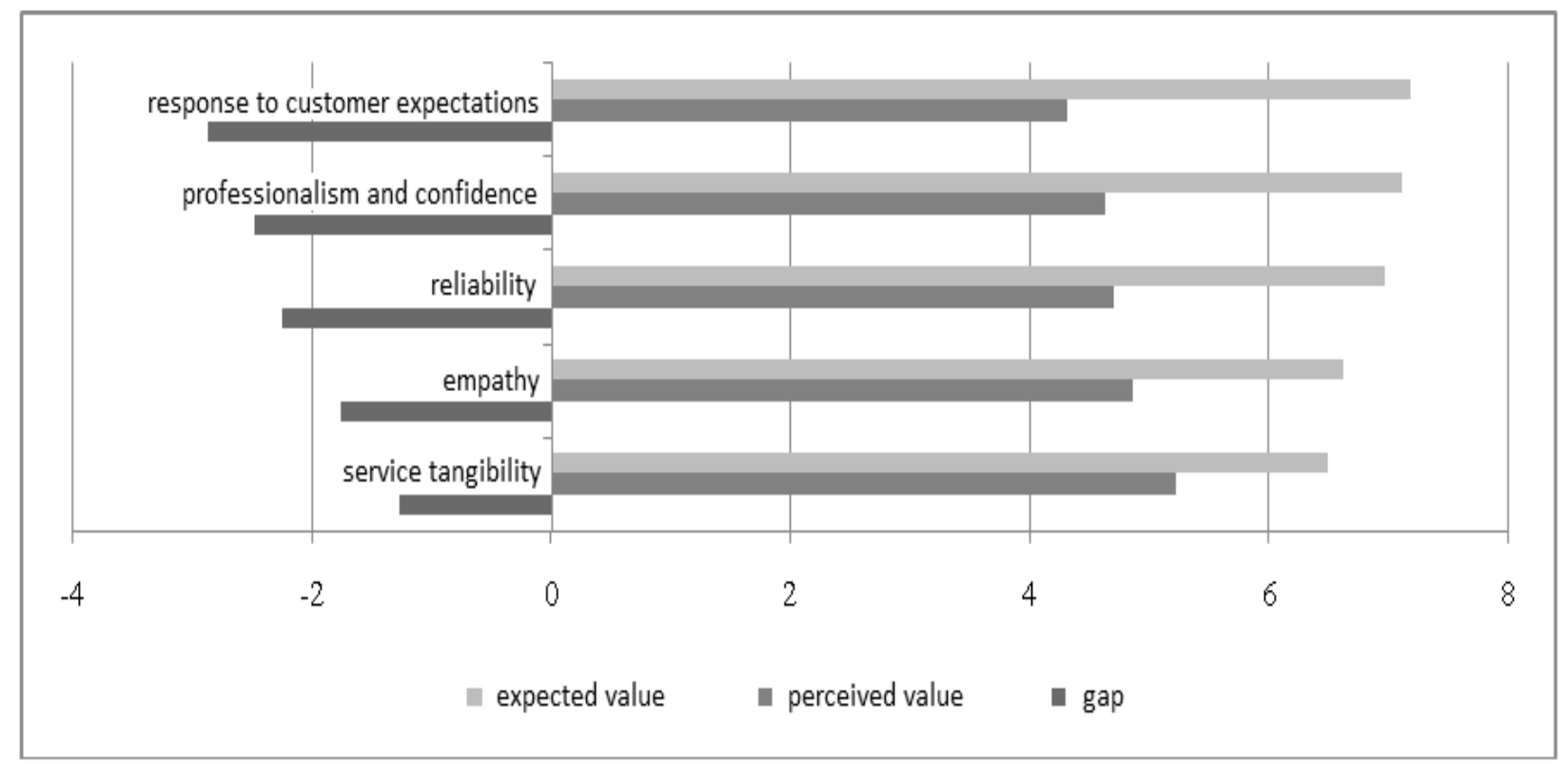

Figure 5. AUTOCASCO insurance service quality in 2013. Source: based on the results of the survey.

Of the above measurements, the service tangibility scored the best possible result (-1.27), comparable to 2012 (-1.24). It indicates that insurance institutions pay the most attention to the tangible aspect of their activity (attractive appearance, good looks), which is the main attribute of contacts with customers and of reliable communication during the process of service delivery. At the lowest level among the studied areas were such factors as the response to customer expectations (-2.87), professionalism and confidence (-2.48), reliability (-2.26), and empathy (-1.76). Like in 2012, these areas showed the greatest differences, which let us claim that the level of insurance service provision is at the low level, while customer expectations as to the studied insurance are not fulfilled.

In the next stage of the research, the weighted average insurance service quality was calculated in each of the studied areas. Analyzing the data acquired in 2012-2013, we may state that the most important area for the respondents was the response to customer expectations, while the service tangibility was of minor importance. Bearing in mind the importance of the studied dimensions for the customer, in 2013, the total average of AUTOCASCO insurance service quality was -0.42 . In 2012, the weighted average insurance service quality was -0.46 , which means that in 2013 , the value decreased by -0.04 , which indicates a low level of services, as well as unfulfilled customer expectations (see Figure 6).

Considering the place of residence in AUTOCASCO insurance service quality in 2012-2013, the arithmetic average in every studied areas was negative (see Figure 7). 


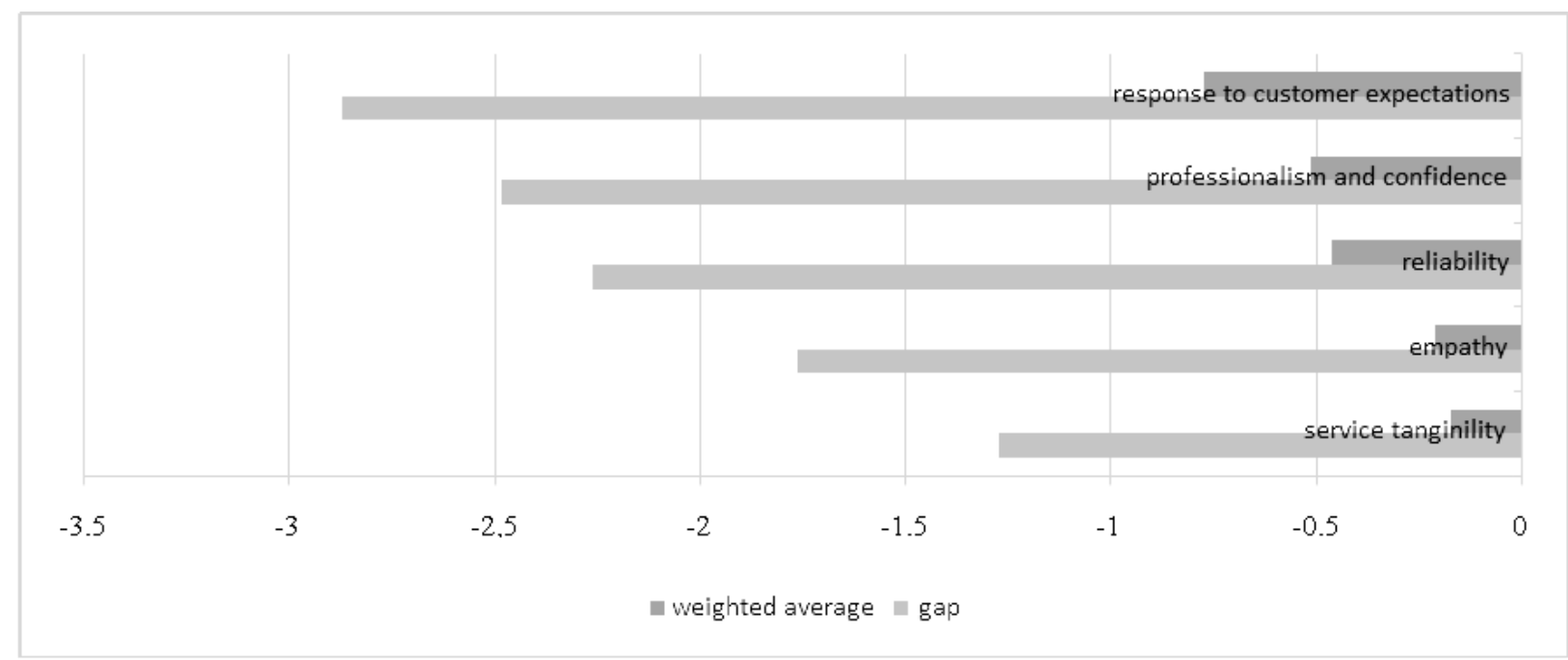

Figure 6. The AUTOCASCO insurance service quality according to two measurements: the gap and the weighted average in 2013. Source: see Figure 5.

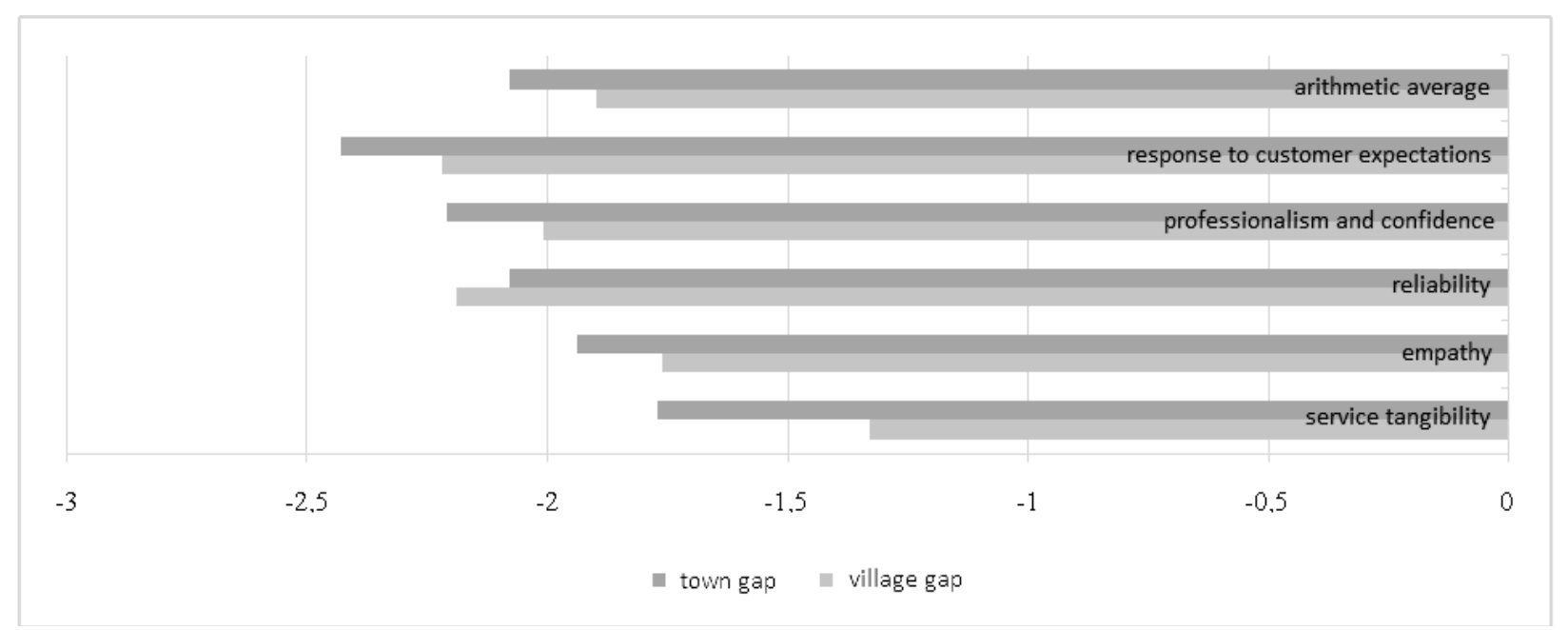

Figure 7. The AUTOCASCO insurance service quality in the opinion of respondents and their place of residence 2013. Source: see Figure 5.

Considering town residents, the arithmetic average in every studied area in 2013 was -2.08. In 2012, this value reached -2.05 . This result confirms the opinions of respondents residing in towns. In the above survey, the lowest were: the response to customer expectations $(-2.43)$ and professionalism and confidence $(-2.21)$. These areas exceeded the Servqual average (-2.08). In comparison with 2013, in terms of the first area, in 2012, this value rose by 0.12 , while in the second area, the difference was 0.03 . The average result reached by town residents in 2013 was higher than the general average which amounted to -1.99 , whereas in 2012, the result stood at -1.94 . The difference in average results in the studied periods is slight $(-0.05)$, which indicates that town residents feel greater dissatisfaction with the studied insurance, and the level of the service provided is still low. Considering village residents, the average difference between customer experiences and expectations of the AUTOCASCO service in 2013 was estimated at -1.9. Compared with 2012, the arithmetic average was -1.85 , which indicates that the service provision quality still brings unsatisfactory results. Assessing service provision quality at this level, in 2013, the arithmetic average for both groups was -1.99 , while in 2012 , it stood 
at -1.95. This situation still indicates dissatisfaction among village residents. Comparing both research groups in 2012-2013, in terms experience and expectation of the AUTOCASCO service provided, only in the area of reliability, the results are similar. The greatest difference was noted in the area of service tangibility. The value of this indicator stood at -0.44 in 2013, in comparison with 2012, when the difference in this area amounted to -0.46. Analyzing the research group in terms of age, in 2012, the greatest dissatisfaction with the quality of the offered service was observed among over-45-year-olds (-2.09), whereas among 18-35-year-olds, the lowest level of satisfaction was observed (-1.81). Comparing the results of 2013, it can be noted that the situation was similar. The quality of offered services did not meet the total expectations of over-45-year-olds $(-2.14)$, while among the 18-35-year-olds, the satisfaction with the quality of services provided was slight (-1.88). From the conducted survey, it can be concluded that people who have more extensive experience, and continuously use the services provided by intermediaries in the insurance market, can assess the level of quality of offered services much more easily than young people with limited knowledge and experience.

\section{Conclusions}

Insurance companies as institutions operating in the financial market, should provide services of the highest quality. High quality of insurance services ensures efficient functioning and a growing number of customers who pass their risk onto an insurance institution. Hence, the insurer will hold a strong position in the market and the customer will receive the insurance service of appropriate quality (Nieżurawski, Pawłowska, \& Witkowska, 2010).

The research conducted allows forming a number of important conclusions:

The way a service is delivered should aim at responding to and accepting customer needs, while failing to respect customer rights contributes to the negative effects that influence the organization environment.

Creating a negative image of an insurance institution will make it difficult to create an efficient quality management system.

What determines customer satisfaction with the quality of provided services is not the place of residence, but the age of people using the services offered by an insurance institution.

From the research conducted in the years 2012-2013, it can be concluded that the tangible aspect of insurance institutions is the main attribute in direct contacts with a customer in the process of service provision. Insurance service quality is also determined by such factors as: professionalism and confidence, reliability of service provided, empathy and prompt service delivery.

The average Servqual result in 2013 was at -1.99 , while in 2012, its value amounted to -1.94 , which indicates a moderate discrepancy between customer experiences and expectations, while the weighted average Servqual result amounted to -0.42 in 2013 and -0.46 in 2012, which proves that the level of service quality provision is at a moderately low level, which results from failure to fulfill customer expectations.

\section{References}

Borkowski, S. (2012). Toyotaryzm. The test results BOST (pp. 6-7). Warsaw: PTM Publisher.

Chłodnicki, M. (2005). The development of professional services. In K. Kłosiński and U. Kłosiewicz-Górecka (Eds.), Services in socio-economic development (p. 206). Warsaw: IRWiK.

Ferrell, S. F., \& Ferrell, W. G. (1994). Using quality function deployment in business planning at a small appraisal firm. The Appraisal Journal, 62(3), 382-390.

Garczarczyk, J. (2002). Quality of service as a condition of the insurance management. In T. Sangowski (Ed.), Insurance market economy (p. 291). Bydgoszcz; Poznan: Publishing House Brant.

Garczarczyk, J. (2004). Model-quality financial services in Poland (pp. 19-20). University of Economics in Poznan. 
Gierszewska, G., \& Romanowska, M. (2009). Strategic analysis of the company (pp. 11-25, 4th ed.). Warsaw: PWE.

Grönroos, C. H. (1978). A service oriented approach to marketing of service. European Journal of Marketing, 12(8), 36-45.

Grönroos, C. H. (1984). A service quality model and its marketing implications. European Journal of Marketing, 18(4), 36-44.

Gronroos, C., \& Gummesson, E. (1985). Service marketing—Nordic school perspectives (pp. 33-45). Stockholm University, Stockholm.

Gummesson, E. (1987). Quality-The Ericsson approach (p. 167). Stockholm: Ericsson.

Gummesson, E. (1996). Quality management in service organizations. An international of the service quality (pp. 219-221). Phenomenon and Synthesis of International Research, Karlsfed.

Haffer, M., \& Karaszewski, I. W. (Eds.). (2009). Growth factors competitiveness of enterprises and regions (p. 694). Torun: Publishing House of Nicolaus Copernicus University.

Hemmasi, M., Strong, K. C., \& Taylor, S. A. (1994). Measuring service quality for strategic planning and analysis in service firms. Journal of Applied Business Research, 10(4), 25.

Johnston, R. (1995). The determinants of service quality: Satisfiers and dissatisfies. International Journal of Service Industry Management, 6(5), 53-71.

Kowalewski, E. (2006). Business insurance law (p. 778, 3rd ed.). Bydgoszcz; Torun: Publishing House Brant.

Leśniewski, M. A. (2013). Eco-developmental sources of competitiveness of municipalities in Poland (pp. 145-148). Warsaw: CeDeWu.

Liker, J. K., \& Hoseus, M. (2009). Toyota culture. The heart and soul of the philosophy of Toyota (pp. 21-26). Warsaw: MT Business Publishing.

Liker, J. K., \& Ogden, T. N. (2011). Toyota under fire. The use of the opportunities that the crisis brings (pp. 35-37). Warsaw: MT Business Publishing.

Niestrój, R. (2004). Marketing management-Strategic issues (p. 203). Warsaw: PWN.

Nieżurawski, L., Pawłowska, B., \& Witkowska, J. (2010). Customer satisfaction. Strategy-measurement-management (pp. 274-275). Torun: Publishing House of Nicolaus Copernicus University.

Parasuraman, A., Zeithaml, V. A., \& Berry, L. L. (1985). A conceptual model of service quality and its implications for future research. Journal of Marketing, 49, 41-50.

Payne, A. (1996). Marketing services (p. 21). Warsaw: PWE.

Peters, T. J., \& Waterman, R. H. (2011). In search of excellence in business (p. 367). Publishing MT Business.

Przybytniowski, J. W. (2003). The service in the insurance. Insurance News, 9-10, 58-62.

Przybytniowski, J. W. (2010). The importance of insurance brokerage in the structure of business insurance (p. 260). Warsaw: Village of Tomorrow.

Przybytniowski, J. W. (2011). Internet-A chance or threat for development of insurance broker market (selected issues). In St. Borkowski and J. Rosak-SzyrockA (Eds.), Toyotarity. Reflections on the improvement (pp. 166-188). Dnipropetrovsk: Yurii V. Makovetsky.

Przybytniowski, J. W. (2013). The competitiveness of insurance brokerage services market in Poland (pp. 92-93). Warsaw: Publisher PTM.

Przybytniowski, J. W. (Ed.). (2002). Fundamentals of business insurance. Legal status as at 20 July 2001 (p. 160). Kielce: WSH in Kielce.

Przybytniowski, J. W., \& Lubas, B. (2009). Determinants of the quality management system formation for insurance services in poland and in the world, sustainable enterprises of the future (pp. 234-242). Robert Morris University, Pittsburgh, Pennsylvania, USA.

Rogoziński, K. (2000). New marketing services (p. 257). Poznan: Poznan University of Economics.

Rogoziński, K. (2005). Quality of service in the horizon axiological. Quality Issues, 1, 24-33.

Romanowska, M., \& Trocki, M. (2004). The process approach in management (p. 388). Warsaw: School of Economics.

Rudawska, E. (2000). The role of quality in creating customer loyalty banks. In K. Rogoziński (Ed.), Marketing professional services (p. 188). Poznan: University of Economics.

Siemieniako, D. (2010). The role of empathy in building customer loyalty relational, scientific papers. University of Szczecin, Issues Management, Finance and Marketing, 15(608), 19-27.

Stoma, M. (2012). Models and methods of quality measurement (2nd ed.). Lublin. Retrieved from http://www. qrpolska.pl/files/file/M3.pdf

Storbacka, K., \& Lehtinen, J. R. (2001). The art of building lasting relationships with customers (p. 14). Krakow: ABC Publishing. 
Sułkowska, W. (2000). Barriers to the development of the Polish insurance market (pp. 51-72). Krakow: Zakamycze.

Szromnik, A. (1998). Psychosocial factors changes the Polish insurance market. Insurance News, 9-10, 43-44.

Szromnik, A. (2001). The insurance market. Social problems of formation and functioning (p. 62). Krakow: University of Economics in Krakow.

Welch, J. (2005). Winning means to win (p. 56). Warsaw: Publishing Studio EMKA.

Zeithaml, V., \& Bitner, M. (1996). Services marketing, McGraw-Hill. In T. Sangowski (Ed.), Insurance market economy (p. 115). Bydgoszcz; Poznan: Publishing House Brant. 